\title{
Institutionalizing innovation in welfare local services through co-production: toward a Neo-Weberian State?
}

\author{
Francesca Campomori ${ }^{1}$ (D) and Mattia Casula ${ }^{2 *}$ \\ ${ }^{1} \mathrm{Ca}$ ' Foscari University of Venice, Venice, Italy and ${ }^{2}$ University of Bologna, Bologna, Italy \\ ${ }^{*}$ Corresponding author. Email: mattia.casula@hotmail.it
}

(Received 19 October 2020; revised 8 September 2021; accepted 8 September 2021; first published online 11 October 2021)

\begin{abstract}
Innovative practices based on the involvement of citizens as co-producers of welfare local services have been increasingly adopted by the public sector to effectively tackle emerging social problems. Despite the development in the literature on this subject, recent studies still do not clearly indicate which are the challenges for the institutionalization of such practices. By applying a governance lens to the analysis of co-production of local public services, this article aims to contribute to bridging this gap through the empirical analysis of the childcare experience in four European cities. More in detail, it debates the concepts of co-production and innovation in public service delivery within the context of the different waves of public administration reforms; and it investigates how three different sets of conditions - namely, state support and capacity; organizational cultures which support innovation; and integration with facilitative technologies - integrate to facilitate or hinder the institutionalization of co-production initiatives. The findings show that the enabling role of the state actor is a sine qua non to guarantee an institutionalization of these practices, particularly concerning the promotion of trust-building processes. Doing so, the article contributes to the international debate about the possible co-existing of the paradigms of public administration that are arising in the last decades to remedy the problems with the New Public Management; and it provides professionals working in public management and administration with key policy recommendations for the elaboration of new governance systems for the provision of social and welfare services.
\end{abstract}

Key words: Governance; local government; participation; public administration

Institution building is a difficult task. But what makes it so difficult? How does it happen in spite of its difficulties? And how come that human efforts often turn out to be self-defeating? (Giovan Francesco Lanzara 1997, p. 4)

\section{Introduction}

During the last few decades, political scientists engaged in welfare policies research have been showing an avid interest in the study of co-production of local public services (Steen et al., 2016; Bussu and Galanti, 2018; Sinclair et al., 2018; Polizzi and Bassoli, 2020). Innovative practices based on the involvement of citizens as co-producers of welfare services are considered as new ideal practices that welfare systems should incorporate to effectively tackle emerging social problems (Osborne and Strokosch, 2013; Gasparre and Bassoli, 2020). Co-production has thus

(C) The Author(s), 2021. Published by Cambridge University Press on behalf of the Società Italiana di Scienza Politica. This is an Open Access article, distributed under the terms of the Creative Commons Attribution licence (https://creativecommons.org/licenses/by/4.0/), which permits unrestricted re-use, distribution, and reproduction in any medium, provided the original work is properly cited. 
increasingly been included among the 'magic concepts' used by policymakers to frame and support local welfare reforms (Vennik et al., 2016; Profeti and Tarditi, 2019).

Nevertheless, not all that glitters is gold: even in those countries where innovative practices based on a constant interaction between public servants and citizens/users have long been among the tools of government (e.g. in the UK), the problem of sustainability over time is often present (Durose et al., 2017). Actually, the issue of challenges and potential barriers in the institutionalization of innovative practices based on co-production emerges. Since the longterm survival and the improvement of these practices require a deep change in actors' relations and behaviors, as well as in the organizational settings, the risk of weakness and short-livedness is right around the corner. Despite the undisputed interest that policymakers, practitioners, and scholars showed toward this issue in the last decade, empirical researchers on factors challenging the institutionalization process of co-production practices in the realm of social policies have been until now limited. What is more, when and where empirically investigated, these issues have been addressed only partially and unsystematically (see for instance Joshi and Moore, 2004; Pestoff, 2014).

By focusing on those aspects of the institutionalization process related to the infusing with value a practice or an organization beyond the technical requirements of the task at hand, in a way that their objectives and procedures tend to become persistent over time (Selzinick, 1957: 17), this article contributes to this theoretical and empirical debate by answering the following research questions: which factors do users perceive as challenges and/or potential barriers when they are engaged in an attempt of 'instilling value' in co-production practices? Why institutionalization of co-production practices is not an easy and straightforward process?

From a theoretical point of view, this article applies a governance lens to the analysis of co-production and develops a set of theoretical propositions to guide the empirical research based on the working hypothesis that an enabling role of the state actors, rooted in virtuous governance relations with non-state actors, is required to guarantee the institutionalization of these co-production activities. Thus, the article debates the concept of co-production of public services within the different waves of public administration reforms and frames it as a driver of innovation in public services (Nesti, 2018) - especially in the welfare and social ones. The dominant paradigms in public administration research are a fertile ground to analyze the challenges posed to the institutionalization of co-production activities, by virtue of their capacity to focus on different relationships between regular providers and lay actors.

The empirical contribution of this article consists in the assessment of how three different sets of conditions - namely, state support and capacity; organizational cultures supporting innovation; integration with facilitative technologies- integrate to facilitate or hinder the institutionalization of co-production initiatives. The article assesses the factors that citizens perceive as challenges when they are committing to co-production experiences aimed at reconciling work and life and, particularly, what enhances or limits the institutionalization of co-production in childcare. Work-life balance is a new social risk (Steinebach and Knill, 2017) that has been largely discussed during the last decade both at European Union (EU) level (e.g. through the Lisbon Strategy, and Europe 2020), and within the Member States. We analyze four European cities Bologna (Italy), Budapest (Hungary), Thessaloniki (Greece) and Kortrijk (Belgium) - where experiences of co-production in childcare services have been implemented in the last decade following similar trajectories.

Since the concept of co-production has been applied to a variety of research fields, scholars, practitioners, and policymakers emphasized differently, and not always consistent, aspects of this concept: the result has been a lack of consensus toward a shared definition. This article aims at overcoming a too generic depiction of co-production: it mainly concerns the process dimension of the practices based on the involvement of citizens as co-producers of welfare local services (Hartley et al., 2013) and, having in mind the changes that occur in social relations when these practices are implemented, it considers the new governance mechanisms required for 
their institutionalization. Following the definition provided by Osborne et al. (2016: 640), co-production is thus intended in this article as the 'voluntary or involuntary involvement of public service users in any of the design, management, delivery and/or evaluation of public services'.

The article proceeds as follows: section 'Theoretical background' presents the theoretical background; section 'Co-production as an alternative or complementary arrangements for childcare services' introduces co-production in childcare services; section 'Research design and methodology' details the research design and methodology; section 'Findings' presents the results of the empirical analysis; section 'Discussion' discusses the findings; section 'Conclusion' concludes.

\section{Theoretical background}

The provision of public services has been traditionally analyzed through the use of three main models of public administration (Hartley, 2005; Sicilia et al., 2016; McMullin, 2021) - namely the 'traditional public administration (TPA)', the 'new public management (NPM)', the 'new public governance (NPG)' model. Each of them tried to introduce innovative practices in the field of welfare policies, contextually with a different role of the population as co-producer of local services. What makes the NPG model different from the other two reform waves is that the inclusion within the governing processes of a plurality of non-state actors is seen as a necessary condition to better address increasingly complex emerging social problems (Capano et al., 2012), by directly involving citizens in innovative experiments, above all at the local level (Galanti, 2019). Such involvement generates an incremental and collaborative innovation (Bekkers and Tummers, 2018; Hartley and Rashman, 2018): it inevitably alters the traditional bottom-up and top-down logic in citizens' participation for the delivery of local public services (Farazmand, 2017: 606).

These three models are connected with different waves of public administration reforms (Gualmini, 2008), and they are linked to a specific ideology and historical period (Capano et al., 2015; Pollitt, 2016). According to Hartley (2005: 29), these models 'can also be seen as competing, in that they coexist as layered realities for politicians and managers, with particular circumstances or contexts calling for behaviors and decisions related to one or the other conception of governance and service delivery'. What is more, public administration scholars are more and more recognizing that other paradigms of public administration, contextually with the NPG, claimed to remedy the problems with NPM and reinvigorate the public sector during the last few decades (Torfing et al., 2020) ${ }^{1}$ - in particular the Neo-Weberian State (NWS), the Digital Era Governance, and the Public Value Management. These four post-NPM paradigms are not necessarily in contrast to each other, possibly co-existing in their different aspects, although in shifting and unstable relations of dominance (ivi). It is, for example, possible to find in an empirical organization [...] traces of NPM, NPG or other governance concepts in combination with established bureaucratic institutions' (Byrkjeflot et al., 2020: 1002).

Albeit aware of this academic debate on the co-existence of different post-NPM paradigms, this article primarily focuses on the NPG being more suitable to the empirical study of the co-production of local public services, due to the capacity of this paradigm to represent 'a response to the growing fragmentation and pervasiveness of wicked problems that call for crosscutting collaboration and public innovation' (Torfing et al., 2020: 15-16). Consolidated over the last two decades and mainly focused on the supply of welfare policies (Lindsay et al., 2014), this paradigm acknowledges that the state is no longer able to address complex social problems alone (Moon, 2018), and that the traditional government-dominated public-service system is no longer

\footnotetext{
${ }^{1}$ As concerns the adoption of the NPM principles, public administration scholars 'documented the failure to deliver on the promises of deregulation, innovation and cost-efficiency, as well as the negative impact on public service motivation, organizational fragmentation and core bureaucratic values such as fairness, equity and political accountability' (Torfing et al., 2020: 13-14).
} 
effective (Cameron, 2007). A new alternative design for public services is therefore necessary (Casula, 2017a), one which envisages citizens as proactive producers of public services, and no longer only as passive recipients of public services (Osborne, 2010; Nabatchi et al., 2017).

Assuming co-production as a concept that captures these new trends in public administration research, this article argues that, to promote stability and persistence of the co-production practices over time, an enabling role of a state actor is crucial also in an age of governance, since it can nurture relations among involved actors and facilitate the continuity of these practices even in the absence or lack of direct public funding. In other words, the presence of a pro-active public actor able to enter into collaborative governance with co-producers is expected to overcome difficulties in institutionalizing innovation in a post-NPM context. Following the above-mentioned argument that the NPG principles can co-exist with other post-NPM concepts, we are in particular aware that this emphasis on the governing role for the state actors to sustain institutionalizing innovation is also present, contextually with other distinctive elements, within the NWS model, that calls for the 'reaffirmation of the role of the state as the main facilitator of solutions to the new problems of globalization, technological change, shifting demographics, and environmental threat' (Pollitt and Bouckaert, 2011: 118-119).

Based on this theoretical framework, the next two paragraphs illustrate the different meanings taken by co-production and innovation in welfare policies across the three main waves of public administration reforms considered in this article, and introduces the challenges to be tackled for the institutionalization of these practices within the NPG paradigm.

\section{Public administration, co-production, and innovation in public service delivery: three waves}

Until the end of the 1970s, the dominant paradigm in the public administration - namely TPA was based on the separation between politics and administration (Weber, 1968), with the governments that directly provide services to the public and limited active participation of citizens (Hartley, 2005). In this context, 'co-production implies a mix of production efforts by regular producers and consumer producers' (Parks et al., 1981: 1002). Under the involvement of citizens in co-production activities, indeed, there was the belief that, unlike the production of goods, the production and delivery of services is difficult without the active participation of the recipients (Ostrom, 1996: 1079; Ostrom, 1999), as the input of citizens was deemed necessary in both hard services (e.g. police, waste management, national security) and soft services (e.g. education, health, disaster management) (Sorrentino et al., 2017). The reform of the TPA model toward the NPM paradigm (Hood, 1991) was characterized by the introduction of managerial tools and market-type mechanisms inspired by the private sectors logics for the delivery of public services (such as contracting-in and/or outsourcing of services, a focus on performance, organizational specialization, etc.). In this context, the conception of co-production drastically changed, with the latter starting to be considered as a new policy tool that governments can use to increase the effectiveness in the delivery of public services (Alford, 2009). In contrast with this manufacture-dominant approach of the NPM (Osborne and Strokosch, 2013), NPG presents a service-dominant approach, where co-production becomes a central aspect of public service delivery (Pestoff, 2012) through an emphasis on partnerships between private and public organizations, the third sector, and the service users (Vesan and Sparano, 2009; Sørensen and Torfing, 2011). The role of the latter is now qualitatively different from manufacturing and services, as they are co-produced by the service provider and consumer of the services (Osborne, 2010). In this context, the inclusion of a plurality of actors within the governing processes is considered as a practical way to address increasingly complex social problems (Sorrentino et al., 2016), with the engagement of citizens in public service delivery that reinvigorates the achievement of public purposes (Sorrentino et al., 2017) and allows for innovation to be better adapted to the users and their community (Lévesque, 2013; de Vries et al., 2018). As the OECD noted (2011), indeed, citizen participation is more important for the delivery of social services than 
in the general services. This helps explaining why co-production has become, during the last few decades, a desired tool for delivering welfare and social services in many countries (Pestoff, 2006; Verschuere et al., 2012).

The different waves of public administration reforms also reflected a different conception of how innovation should be pursued in public services delivery, especially in the social and welfare field. As Lévesque (2013: 25-39) has noted, while in the TPA some large-scale, national and universal innovations were present (compare social safety nets in welfare state), the NPM model pushed toward the introduction of radical innovation in organizational forms and processes rather than content (e.g. unification of organizational structures in educational and school services). Innovation in the public administration started to be collaborative and incremental in the NPG model with an emphasis on collaborative partnerships, and participatory governance (Sorrentino et al., 2018). In this context, new forms of inclusive, participatory, and democratic governance had to be created, with the empowerment of both informal groups with a weak structure and disadvantaged citizens/users. It firstly involved the introduction and the use of innovative practices to improve social and welfare services. The use of these innovative practices within the NPG paradigm, therefore, implies an interweaving of processes that can involve promoters, agents of change and social entrepreneurs, as well as the service recipients. It follows that state actors and civil society should constantly interact to create new synergies and reinforce the positive elements they are able to provide - the former in terms of innovation, the latter in terms of redistribution.

\section{Institutionalizing co-production: concept and challenges}

The concept of institutionalization has been defined in different ways with substantial variations among approaches, which correspond to the many faces of institutional theory (for an insight on the debate, see Scott, 1987).

This article draws on Selznick's (1957) classical approach and intends institutionalization as a process of infusing with values organizations in a way that their objectives and procedures tend to become persistent over time. If before institutionalization an organization has only instrumental utility, the process of instilling value supplies intrinsic worth to a structure (Scott, 1987). In a similar vein, also Stinchcombe (1968) argues that institutionalization coincides with certain stability over time, even if his interest is focused mainly on identifying how power in institutions is maintained. While in his early work Selznick emphasized the unintended nature of institutional processes, in his late writings he argued instead that this process is not entirely spontaneous nor automatic, but it requires a conscious design and will of overcoming a precarious structure (Scott, 1987: 494). This means that some specific tools and actors must be consciously activated to promote institutionalization. Notwithstanding his useful definition of the concept, Selznick is silent about how the values are infused and about which kind of conscious design is needed: he does not tell us how the process of institutionalization actually takes place. For this part of the story, other scholars and researchers come to our aid in the field of organization studies and co-production practices.

As for the former, we find particularly explanatory what Lanzara (1993) wrote about 'ephemeral organizations': in his view, they are informal organizations arising mainly as a result of natural disasters (such as earthquakes) and carrying out a very intense and relevant emergency relief task in the days immediately following the catastrophe. As quickly as they have appeared, these organizations tend to disappear in a short time, partly because they run out of resources and partly because of difficult interaction with formal institutions. Although Lanzara (1993) is more interested in investigating the emergence and the features of ephemeral organizations than the issue of institutionalization, his analysis clearly reveals that the persistence of organizations largely depends on the economic and human resources at their disposal, on the organizational skills of the leaders and on the relationships with the government bureaucracy. 
On the other side, scholars who studied co-production for delivering social services from a normative stance pointed out that a crucial factor for a longer-lasting success of innovative organizations should be their competence to be guaranteed 'from above', both financially and legally (Vitale, 2009: 172; Pais et al., 2019). To put it another way, it is paramount to find political and administrative allies at various levels with which to negotiate a degree of protection and promotion. Ultimately, scholars unanimously recognize a central role of the state actor in dealing with the process of institutionalization of practices made by social networks with varying levels of formalization. However, it does not mean that the state has to be intended as an automatic driver of institutionalization per se (i.e. possibility for an organization or a practice to persist over time and possibly to expand its range of action). According to Lanzara (1993), the encounter between state bureaucracies and ephemeral organizations can lead to the disappearance of the latter. Public intervention on informal social networks, especially in a governmental area such as social policy (including education) is a tricky issue: while governments cannot avoid encountering them to guarantee they pursue collective goals, the risk of introducing an excess of formalization and rigidity is real (Schon, 1989).

Several studies have also underlined the importance of knowledge and skills, resources and tools, and time in getting the citizens to engage (e.g. Alford, 2002; Jakobsen, 2013). At the same time, the new non-traditional forms of co-production are adding complexity for the public and private organizations involved (Sicilia et al., 2019), by requiring their adaptation to the preexisting governing capabilities and competences (Howlett and Ramesh, 2017). In other words, new effective administrative structures and processes of both state and lay actors (Alford, 2009), as well as strong institutional coordination among the actors involved, become a condition for the institutionalization and routinization of these practices (Rutter, 2016).

Another point raised by scholars relates to cultural obstacles innovative organizations face when attempting to creatively tackle social problems (Chalmers, 2012: 22-23). Both governmental and philanthropic organizations are risk averse (Osborne and Brown, 2011; Bovaird et al., 2015) and largely tend to reject disruptive solutions, i.e. innovations that will alter social systems and structures in favor of incremental improvements, or innovations that will address market failures more effectively (Nicholls and Murdock, 2012). For social innovators, moreover, it is difficult to both identify and gain access to the networks that will facilitate their success (Jessop et al., 2013). As explained by Chalmers (2012: 23), 'this reduces exposure to valuable sources of knowledge that may subsequently feed into the social innovation process'.

Finally, the more recent forms of co-production are challenging the existing and traditional service paradigm since the relations between service professionals and service users are more and more mediated and enabled by ICT-based platforms (e.g. web 2.0 platforms, mobile devices, social media, etc.). These technologies allow citizens to be part of a collaborative web-based mode of producing public services (Kannan and Chang, 2013; Lember et al., 2018). If these digital and technological factors are expected to improve the efficiency and the effectiveness of service delivery, their correct use introduces new challenges for the actors involved. As explained by Meijer (2012), the benefit of technology is conditional to the policy domain and the institutional situation in which it is used, and it is mainly subordinate to the presence of citizen communities that are both capable and willing to link the shared provision of public services with technology. The main challenges state and lay actors have to face could be, for example, related to fair participation in the delivery of public services, as well as a possible digital divide that could exclude certain social groups from active participation (Casula et al., 2020).

Based on this theoretical background, and in the light of what emerged from the literature on the possible challenges that innovative practices encounter in the institutionalization process, we put forward the following three theoretical propositions:

Expectation 1: Institutionalizing innovation in welfare local services through co-production is more likely when the public actor shows adequate support and capacity to enter into collaborative governance with co-producers. 
Expectation 2: Institutionalizing innovation in welfare local services through co-production is more likely when organizational cultures which support innovation are well developed.

Expectation 3: Institutionalizing innovation in welfare local services through co-production is more likely when innovation is integrated with facilitative technologies and particularly when ICT platforms are affordable for a wide public.

\section{Co-production as an alternative or complementary arrangement for childcare services}

Childhood education and care, as an important part of work-life balance initiatives, is a case in point to explore the challenges to sustain innovation in family policies.

Reconciliation of work and family life is considered one of the most prominent new social risks in the EU. ${ }^{2}$ Austerity measures introduced cuts in public spending and often raised fees for accessing public services, including care-related ones; at the same time, the economic crisis is associated with job losses, pay cuts, and temporary and informal work. ${ }^{3}$ The increased number of workers on compressed week schedules brings about lights and shadows at the same time. This situation often entails more time available for social activities and parenting, but low-skilled workers struggle to make a living and are beholden to the needs of corporations. Actually, in the last few decades, there has been a decline in the average working time, yet an increase in unpaid overtime has also been recorded. This reveals significant implications for the work-life balance of families: there is clear evidence that for low-income families, in particular, and for those where both parents are working, childcare issues are a challenge now more than ever.

Within this scenario, three situations, in particular, make the emergence of alternative or complementary arrangements to formal childcare services more likely (Rutter and Evans, 2011): (1) when the opening hours of the childcare service are not sufficient, as a supplement of formal care and as after-school and holiday provision for school-age children; (2) when children are very young; (3) when regular childcare arrangements are insufficient, as emergency or back-up service.

Parents' participation in childcare service is one of the possible responses to the decline in governance capacity at the local or national level (Joshi and Moore, 2004: 41): when the government does not provide childcare services very effectively, in terms of work-life balance needs, groups of citizens (parents) can act to help overcome deficiencies. Participation takes different forms, be they economic, political, pedagogical or social forms (Pestoff, 2006: 512). Pestoff (ibidem) intends contributions of time as a form of economic contributions that mainly consists in parental participation in the running and management of childcare facilities: this article focuses on this type of co-production by analyzing some experiences implemented in four European cities. These experiences are generally born recently and often still poorly structured. The aim of the article, as mentioned above, is to understand the factors that could facilitate or otherwise hinder the institutionalization of such practices, starting from the perception of the users themselves.

\section{Research design and methodology}

The study of the co-production of public services can be adapted to different research fields and situations that require the use of different, and often polarized, scientific methods (Bekkers and Tummers, 2018; Bevir et al., 2019). In line with previous explorative empirical studies that underlined the necessity to qualitatively appreciate them to better identify relevant patterns of behavior and related influences (e.g. Sicilia et al., 2016), an explorative case study approach was used (Yin, 1994; Casula et al., 2021) to analyze the under-investigated issue of the institutionalization of these emerging social problems, through the analysis of innovative experiences of co-production

\footnotetext{
${ }^{2}$ Cfr. Directive (EU) 2019/1158 of the European Parliament and of the Council of 20 June 2019 on work-life balance for parents and carers and repealing Council Directive 2010/18/EU, available at: http://data.europa.eu/eli/dir/2019/1158/oj.

${ }^{3}$ Cfr. European Observatory of Working Life, www.eurofound.europa.eu/observatories/eurwork.
} 
for childcare services in four European cities (Bologna, Budapest, Thessaloniki, and Kortrijk). Although these cities belong to national welfare systems with different features and levels of development, they have all implemented quite innovative strategies for childcare, especially for co-production experiences. Based on the aim of the article, in selecting these cities, we are not interested in making a systemic comparison among them, but rather in discovering any similar patterns in the institutionalization process of innovative practices of childcare.

The field analysis simultaneously made use of different qualitative techniques to investigate all the dimensions under scrutiny.

A preliminary desk analysis of the official reports elaborated by local public authorities about the innovative social practices implemented in the last decade in each city had been conducted. Around 20 official reports published by national and regional organs on social and welfare policies were consulted. Relevant information was also gathered from Internet websites of local authorities and bodies (including third sector organizations). Previous academic research was consulted.

A total of 40 semi-structured interviews (10 for each city) were conducted with local actors in mid-2018 by discussing the barriers and criticalities identified in their daily co-production activities in the field of childcare. An 'expert interview' methodology (Bogner et al., 2009; Littig, 2011; Littig and Pöchhacker, 2014) was used to select informants, which were distributed as follows for each city: four representatives from local organizations working with families, three representatives from the local government, two parents, and one representative from local companies. For the purpose of this research, we considered as 'experts' those having a thorough knowledge of the local context in which these innovative practices are implemented, therefore covering both public and private actors following the theoretical background previously introduced. Interviews lasted approximately 60 min each. Following Della Porta and Keating (2008) recommendations, a low profile was kept, anonymity was guaranteed, and within $24 \mathrm{~h}$, the interviews were manually transcribed and analyzed. Overall impressions regarding the interview and the interviewee were also noted down. This set of interviews had six sections regarding: respondent's background; needs related to childcare and innovative work/life balance initiatives present; key factors to opt for collaborative childcare; organization difficulties encountered; trust and safety; role of technology. In each section, open-ended questions were asked, to better understand the criticalities identified by local actors in implementing innovative practices. At the end of each interview, informants were asked to share any other relevant information.

A web survey was conducted between late 2018 and mid-2019. Informants included parents who were members of the organizations working with families involved during the semistructured interviews. The interviews indicated that a network of parents who were members of these organizations was already involved - as co-producer - in innovative practices in the field of childcare in each of the four cities. Following the snowball technique (Atkinson and Flint, 2004; Morgan, 2008) in selecting the potential respondents to the web survey, it was considered appropriate to start from a small group of initial informants for each of these organizations and then extend the analysis and reach a new segment of the population. The survey had four sections related to: respondent's background (including certain socio-demographic characteristics, such as gender, age, education level); digital technology usage for childcare activities; ease of learning, adoption, or interest in digital technologies for childcare activities; trust. Scaling, closed and open-ended questions composed the survey, which involved a total of 385 respondents (117 from Bologna, 107 from Kortrijk, 84 from Thessaloniki, and 77 from Budapest). This sample in the database had the following characteristics: the survey was mostly filled in by women (78.9\%), with a clear overrepresentation of females in every city; respondents were mostly couples with children, with the sample ranging in the four cities between 87 and 94.7\%; the overall mean score is 1.75 children per household, with no significant difference in the average amount of children per household among the four cities; the average age of the overall database is 41 years old, with the sample of Budapest having the youngest average age (with $81 \%$ 
between 31 and 40 years old) - followed by Kortrijk; in all the cities, participants are highly educated, with a large number of participants having a postgraduate degree; in all cities, the primary nationality is native.

Based on this field analysis - which has simultaneously used different techniques to better investigate the issues under scrutiny - the data analysis procedure was based on a triangulation of all the primary and secondary data collected. This procedure checked the validity of the study. To this purpose, it is necessary to specify that the quantitative data collected within the web survey were only used as descriptive statistics, to support the abundance of reliable qualitative data previously collected. More in detail, guided by Eisenhardt's notion that 'analyzing data is at the heart of building theory from case studies' (Eisenhardt, 1989: 11), this data analysis was aimed to identify common trends in the four cities, based on the three theoretical propositions advanced, related on: (a) state support and capacity; (b) organizational culture which supports innovation; and (c) integration with facilitative technology. As indicated in previous paragraphs, the use of alternative arrangements in childcare presents characteristics, potentials, and limits that are similar across Europe. Particular, and specific, elements that emerge from the analysis of each city have been however underlined if they significantly differ from the other three cities. Representatives from local public authorities and of the third sector were consulted to validate the results once they were completed.

From an analytical point of view, the final output was therefore the construction of a policy narrative (Fischer and Forest, 1993) of how these different sets of conditions integrate to facilitate or hinder the sustained operation or institutionalization of co-production initiatives, based on the above-mentioned theoretical background. These policy narratives are presented in the next two sections.

\section{Findings}

\section{State support and capacity}

In each of the four European cities, several organizational barriers related to the public sector were identified. The most common is the inadequacy of municipal services for post-school childcare activities. Another critical aspect related to state support concerns the system of public calls to finance local organizations to help families in their work/life balance initiatives. This critical aspect is related to the extreme parceling of local associations, which also do not display a strong organizational structure nor abundance of resources. That creates several problems related to the participation of these associations in public calls, as well as in financial reporting: the main problem underlined is the lack of financial and human resources, which causes major obstacles for any new or additional initiative to provide solutions to parents. The Municipality of Bologna tried to bridge this gap by promoting the 'collaboration pacts' ( patti di collaborazione) - a financially and organizationally leaner tool compared to traditional public tenders, because it allows different financial reporting and is also open to associations without legal personality. However, collaboration pacts are not commonly used for childcare activities, and when used in this policy sector, their implementation is poor, since small associations - which are the majority in Bologna (Casula, 2015, 2017b) - are not always able to access these pacts, as in several cases a financial commitment to repayment is required.

In this general context, the civil society agrees that there are two main conditions that would favor a stable engagement of parents in co-production practices based on exchanging time and support: the first condition is that the presence of a clear regulation is essential from the very beginning $^{4}$; the second condition is that the role of the state actors in supporting co-production initiatives is essential and should consist, for example, in providing public spaces, events, and

\footnotetext{
${ }^{4} \mathrm{By}$ way of example, here the words of a parent interviewed in Kortrijk: 'there must be trust and a clear regulation. In this way there are the same rules and conditions for all. It's also useful that there will be a reference person'.
} 
training courses. In Thessaloniki, for instance, interviews emphasized the importance of creating a helpdesk to increase confidence and trust by the parents.

\section{Organizational cultures which support innovation}

Field analysis showed that state support and capacity also affect the improvement of innovative organizational cultures capable of supporting actual co-production practices: the lack of a state actor creating trust between people turned out to be a critical issue in institutionalising innovative social practices based on co-production. The interviews clearly indicated that citizens/parents expect the state to help them overcome these barriers, which can be unbridgeable, especially to create stable and lasting relationships with new parents beyond their own network (on which the idea of co-production is essentially based). According to several stakeholders interviewed, for example, a sort of informal 'family support center' is present in each of the four cities, but without the possibility of being extended outside the members of the original families.

'Co-production is done with the citizens, not by sticking to family ties or friendship ties' said a parent interviewed in Budapest. More in general, the findings highlight the lack of a bond that could overcome the problem of the poor knowledge of those close by: to create such practices there is a fundamental issue of trust toward unknown people, and citizens demand specific moments for 'trust-building'. Thus, due to the barriers and criticalities identified, safety and trust were considered as two fundamental elements to guarantee a correct system of mutual exchange in this field. If trust is lacking in both the individual people and the organizations involved, then the conditions completely fail. According to the interview of a representative of a local organization working with families in Thessaloniki, 'the focus is to create relationships of trust, which sometimes do not depend on a decade of knowledge but on the quality of the relationship between people'. More in general, in each of the four cities, interviewees believe that the lack of trust could raise a wall among the participants, and they suggest the organization of special activities organized in collaboration with the Municipality as a solution to overcome this barrier. They proposed, for example, dedicated activities to get to know each other better (e.g. an afternoon 'meet and greet' group to talk about child-rearing ideologies), starting with open events but going deeper with common workshops.

\section{Integration with facilitative technologies}

Our data show that the use of electronic platforms to favor co-production activities in the field of childcare, although at the beginning it may have seemed somewhat 'strange', was admitted as an interesting tool to manage the problems of the everyday routine of childcare and also for some urgent situations.

In the total database, $32.3 \%$ is currently using an online platform to support childcare activities. Furthermore, $22.2 \%$ is using an online calendar to take note of childcare- and work-related tasks, with the City of Kortrijk (47.3\%) and Budapest (27.9\%) having the highest percentage of participants using an online calendar. Both activities do not seem to be very used, which means that there could be potential for increased usage of technology in supporting activities. On the other hand, it could also require a greater effort in changing the current processes and mindset of people. However, participants are quite confident that it will be easy for them to learn how to work with new technologies $(M=4.35)$. Furthermore, participants generally feel keen to try out digital technologies $(M=3.96)$ and are interested in them $(M=3.87)$.

In general, technology only seems able to help making the implementation of innovative practices easier. In other words, technology is only able to help and consolidate the relationships among parents and groups that already know each other. In addition to the survey where around $70 \%$ of the interviewees declared to have difficulties in trusting other people to implement these practices in the field of childcare, this assumption clearly emerges, for example, through the 
analysis of a practice of digital social innovation, called Cokido, consolidated in Belgium and financed by the Kortrijk Municipality. What emerges from the Cokido experience is that the digital platform itself does not create trust and confidence: to correctly implement digital social innovative practices, the use of online activities within the electronic platform has to be preceded by already-existing trust, as the digital tool is unable to replace trust arising from face-to-face encounters.

\section{Discussion}

It is time to return to the working hypothesis and the propositions advanced in the theoretical section to evaluate them in the light of the case studies and to see how the three conditions integrate each other.

In light of the first theoretical proposition advanced on the role of the state actor, research shows that a weak role of the public actor in supporting co-production practices - e.g. by facilitating the participation of local associations with less organizational strength, but also by providing space and services to the experiences that arise - constitutes a very concrete barrier to the possibility of development and survival of such practices. The state actor has also proved to be crucial for the role that private actors attribute to it in strengthening bonds of trust, which are essential for the activation of such practices beyond a restricted sphere of users and to promote their institutionalization.

This last point closely links the first theoretical proposition with the second one, referring to organizational cultures. The interviewees have repeatedly stated that building trust is essential to extend co-production experiences to a wider circle and make it possible for them to be infused with value. At the same time, the interviewees attribute to the state the task of coordinating the building of trust. Indeed, innovation-oriented organizational cultures are more likely to become institutionalized where the state actor creates opportunities and spaces that foster trust among users.

The role of trust, and therefore indirectly the role of the state, also return to the theme of integration with facilitative technologies (Expectation 3): technology is considered an added value in co-production practices, and it would certainly be unlikely to do without it for very practical reasons, e.g. it would be very difficult to overcome organizational difficulties of making arrangements with each person individually. However, technology does not replace the trust that is created in face-to-face relationships, and which is also partly strengthened by feeling part of an organization that in some way monitors the profile of new members who join a group of users.

To summarize, a state actor that supports co-production practices strengthens the relationships of trust that go beyond the consolidated circles of users and allow both an expansion of co-production practices and their institutionalization. Technology is a precious ally in the development of co-production practices as long as it is accompanied by the care of face-to-face relationships in which an institutional actor acts as an intermediary.

\section{Conclusion}

This article has contributed to the emerging literature on co-production by empirically investigating the different challenges that can hinder the institutionalization of innovative practices based on the involvement of citizens as co-producers of welfare services. Co-production has been identified as a government tool increasingly used within the NPG paradigm and a driver of innovation in welfare services. Doing so, this article has provided an advance in the literature on innovation issues, not simply limited to the private sector but which takes into account the role of the public administration within the innovation processes.

Through the analysis of similar childcare experiences in four European cities, the article empirically examined the challenges that the co-production experiences face to persist over 
time. In arguing that a strong role of state actors has to be present to guarantee an institutionalization of these practices, the findings also show how relevant trust-building is for the issue. Trust has emerged transversally in each of the three dimensions considered: in underlining the necessity to create and establish specific conditions to consolidate it, the findings show that trustbuilding is a pre-condition to institutionalize innovative social practices through the use of co-production activities. In other words, although this empirical analysis focused on a small- $N$ qualitative research, the findings provided useful elements in support of the argument that the presence of a top-down regulation appears to be the solution to reduce the risk aversion of the different public and private actors potentially involved in these practices.

Several policy implications arose from this article about the possible role played by public actors in the elaboration of new governance systems for the provision of welfare services. If the long-term implementation of innovative practices requires a drastic change in the behavior of civil society, their persistence over time is subordinated to the state actors' ability to create the conditions for it: even in the NPG model, where state and lay actors concur to the provision of public services, the presence of supportive state actors continues to be a condition to guarantee the institutionalization of innovative practices based on the involvement of citizens as co-producers of local services. Compared to the public administration reforms inspired by the NPM model (that comprised a service-dominant approach), the presence of pro-active citizens in producing public services has become a necessary condition to better address complex social emerging problems. Even though necessary, this condition is not sufficient, since it is subordinated to the presence of state actors with enough capacity and willingness to contribute to the creation of trust among all the actors involved, and to guarantee the presence of adequate organizational structures. State actors are also expected to facilitate the shared provision of local public services using digital technology. Civil society itself calls for regulation by the state because it is aware of facing daily cultural, organizational and social barriers which are difficult to overcome without a targeted and day-by-day accompanying action by local actors.

These results are therefore in line with the most recent debate on the evolution of the public administration models, and the possible co-existence of the paradigms that are arising in the last decades to reinvigorate the public sector and to remedy the problems with NPM. More in detail, this article supports the argument that the NPG paradigm, while safeguarding the principle of pro-active participation of citizens in the production of social and welfare policies, can work in combination with other post-NPM paradigms, and in particular with the NWS. Among other founding principles, the NWS emphasizes the recovery by the state actors of a coordinating role with instruments other than hierarchy, e.g. also through ICT.

Based on the results of this article, future studies should go in, at least, three different directions. As the issue of the institutionalization of innovative social practices is based on the involvement of different types of public and private actors, less investigated so far, future research should explore if there is a correspondence between what we found in the context of childcare and in other areas of welfare where co-production is developing, such as in social work in home-sharing. Similarly, they should also be explored in areas outside the European context, where different welfare systems are implemented contextually with different traditional state-society relationships. Public administration scholars could also start from the evidence collected in this empirical research to contribute to the theoretical debate on public administration reform models about the possible emergence of hybrid organizational models in empirical organizations featured by traces of NPM, NPG or other post-NPM concepts together.

Funding. This work has been funded as part of the project Families Share, European Union's Horizon 2020 CAPS Grant agreement No 780783 .

Acknowledgement. The authors contributed equally to this work. The authors would like to thank Italian Political Science Review's editors and the anonymous reviewers for their valuable advice and comments on previous versions of this paper. 


\section{References}

Alford J (2002) Why do public sector clients co-produce? Towards a contingency theory. Administration \& Society 34, 32-56. Alford J (2009) Engaging Public Sector Clients. From Service Delivery to Co-Production. NY, London: Palgrave Macmillan.

Atkinson R and Flint J (2004) Snowball sampling. In Lewis-Beck MS, Bryman A and Liao TF (eds), The Encyclopaedia of Social Science Research Methods. Thousand Oaks: SAGE Publications, pp. 1044-1045.

Bekkers V and Tummers L (2018) Innovation in the public sector: Towards an open and collaborative approach. International Review of Administrative Sciences 84, 209-213. https://doi.org/10.1177/0020852318761797.

Bevir M, Needham C and Waring J (2019) Inside co-production: ruling, resistance, and practice. Social Policy and Administration 53, 197-202.

Bogner A, Littig B and Menz W (eds) (2009) Interviewing Experts. Methodology and Practice. Basingstoke: Palgrave Macmillan.

Bovaird T, Van Ryzin GG, Löffler E and Parrado S (2015) Activating citizens to participate in collective co-production of public services. Journal of Social Policy 44, 1-23.

Bussu S and Galanti MT (2018) Facilitating coproduction: the role of leadership in coproduction initiatives in the UK. Policy and Society 37, 347-367.

Byrkjeflot H, du Gay P and Greve C (2020) What is the 'Neo-Weberian State' as a regime of public administration? In Ongaro E and van Thiel S (eds). The Palgrave Handbook of Public Administration and Management in Europe. London: Palgrave, pp. 991-1009.

Cameron D (2007) The conservative approach to improving public services. Retrieved from http://conservative-speeches. sayit.mysociety.org/speech/599906.

Capano G, Rayner J and Zito AR (2012) Governance from the bottom up: complexity and divergence in comparative perspective. Public Administration 90, 56-73.

Capano G, Howlett M and Ramesh M (eds) (2015) Varieties of Governance: Dynamics, Strategies, Capacities. London: Palgrave Macmillan.

Casula M (2015) Opportunity structures for citizens' participation in Italian regions: a case study. Journal of Public Deliberation 11, Article 6. [ISSN: 1937-2841].

Casula M (2017a) Who governs in (local) governance? Theoretical considerations and empirical evidence. Revista de Administracao Publica-Brazilian Journal of Public Administration 51, 1121-1138.

Casula M (2017b) Adaptation or transformation? Interpreting participation in times of austerity in a (old) red region. PArtecipazione e COnflitto. The Open Journal of Sociopolitical Studies 10, 1005-1036.

Casula M, Leonardi C and Zancanaro M (2020) How does digital technology impact on the co-production of local services? Evidence from a childcare experience. Public Money \& Management. https://doi.org/10.1080/09540962.2020.1728066.

Casula M, Shields PM and Rangarajan N (2021) The potential of working hypotheses for deductive exploratory research. Quality and Quantity 55, 1703-1725. https://doi.org/10.1007/s11135-020-01072-9.

Chalmers D (2012) Social innovation: an exploration of the barriers faced by innovating organizations in the social economy. Local Economy 28, 17-34.

Della Porta D and Keating M (2008) Approaches and Methodologies in the Social Sciences: A Pluralist Perspective. Cambridge: Cambridge University.

de Vries H, Tummers L and Bekkers V (2018) A stakeholder perspective on public sector innovation: why position matters. International Review of Administrative Sciences 84, 269-287.

Durose C, Needham C, Mangan C and Rees J (2017) Generating 'good enough' evidence for co-production. Evidence \& Policy: A Journal of Research, Debate and Practice 13, 135-151.

Eisenhardt K (1989) Building theories from case study research. Academy of Management Review 14, 532-550.

Farazmand A (2017) Governance reforms: the good, the bad, and the ugly; and the sound: examining the past and exploring the future of public organizations. Public Organization Review 17, 595-617.

Fischer F and Forester J (ed.) (1993) The Argumentative Turn in Policy Analysis and Planning. Durham \& London: Duke University Press.

Galanti MT (2019) The last mile: when policies go local. Italian Political Science 14, 1, i-iv.

Gasparre A and Bassoli M (2020) Governance beyond the rhetoric: organizational action, change, and illusion in the Italian local welfare system. Administration \& Society 52, 927-958.

Gualmini E (2008) Restructuring Weberian bureaucracy: comparing managerial reforms in Europe and the United States. Public Administration 86, 75-94.

Hartley J (2005) Innovation in governance and public services: past and present. Public Money \& Management 7, 27-34.

Hartley J and Rashman L (2018) Innovation and inter-organizational learning in the context of public service reform. International Review of Administrative Sciences 84, 231-248.

Hartley J, Sørensen E and Torfing J (2013) Collaborative innovation: a viable alternative to market-competition and organizational entrepreneurship. Public Administration Review 73, 821-830.

Hood C (1991) A public management for all seasons? Public Administration 69, 3-19. 
Howlett M and Ramesh M (2017) The Achilles heels of collaboration: overcoming critical capacity deficits in collaborative governance arrangements? Paper presented at the NUS-FPZG UNESCO Chair Workshop on The Governance of Collaboration: Co-Production, Contracting, Commissioning and Certification, Dubrovnik, Croatia.

Jakobsen M (2013) Can government initiatives increase citizen co-production? Results of a randomized field experiment. Journal of Public Administration Research and Theory 23, 27.

Jessop B, Moulaert F, Hulgard L and Hamdouc A (2013) Social innovation research: a new stage in innovation analysis? In Moulaert F, MacCallum D, Mehmood A, Hamdouch A (eds), The International Handbook of Social Innovation. Collective Action, Social Learning and Transdisciplinarity Research. Cheltenham and Northampton: Edward Elgar Publishing, pp. 110-130.

Joshi A and Moore M (2004) Institutionalised co-production: unorthodox public service delivery in challenging environments. Journal of Development Studies 40, 31-49.

Kannan PK and Chang A (2013) Beyond Citizen Engagement: Involving the Public in Co-Delivering Government Services. IBM Center for The Business of Government.

Lanzara GF (1993) Capacità negativa. Competenza progettuale e modelli di intervento nelle organizzazioni, Il Mulino, Bologna.

Lanzara GF (1997) Perché è difficile costruire le istituzioni. Rivista italiana di scienza politica/Italian Political Science Review 27, 3-48.

Lember V, Kattel R and Tõnurist P (2018) Technological capacity in the public sector: the case of Estonia. International Review of Administrative Sciences 84, 214-230.

Lévesque B (2013) Social innovation in governance and public management systems: toward a new paradigm? in Moulaert F, MacCallum D, Mehmood A and Hamdouch A (eds), The International Handbook of Social Innovation. Collective Action, Social Learning and Transdisciplinarity Research. Cheltenham and Northampton: Edward Elgar Publishing, pp. 25-39.

Lindsay C, Osborne SP and Bond S (2014) The 'New Public Governance' and Employability Services in an Era of Crisis: Challenges for third sector organizations in Scotland. Public Admin 92, 192-207. https://doi.org/10.1111/padm.12051.

Littig B (2011). Interviews, expert. In Badie B, Berg-Schlosser D and Morlino L (eds), The International Encyclopedia of Political Science. London/Thousand Oaks/New Delhi: Sage, pp. 1343-1346.

Littig B and Pöchhacker F (2014) Socio-translational collaboration in qualitative inquiry: the case of expert interviews. Qualitative Inquiry 20, 1085-1095.

McMullin C (2021) Challenging the necessity of new public governance: co-production by third sector organizations under different models of public management. Public Administration 99, 5-22.

Meijer AJ (2012) Co-production in an information age: individual and community engagement supported by new media. Voluntas 23, 1156-1172.

Moon MJ (2018) Evolution of co-production in the information age: crowdsourcing as a model of web-based co-production in Korea. Policy and Society 37, 294-309.

Morgan D (2008) Snowball sampling. In Given L (ed.), The SAGE Encyclopedia of Qualitative Research Methods. Thousand Oaks, CA: SAGE Publications, pp. 816-817.

Nabatchi T, Sancino A and Sicilia M (2017) Varieties of participation in public services: the who, when, and what of coproduction. Public Administration Review 77, 766-776.

Nesti G (2018) Co-production for innovation: the urban living lab experience. Policy and Society 37, 310-325.

Nicholls A and Murdock A (2012) The nature of social innovation. In Nicholls A and Murdock A (eds), Social Innovation: Blurring Boundaries to Reconfigure Markets. Hampshire: Palgrave MacMillan, pp. 1-32.

OECD (Organisation for Economic Cooperation and Development) (2011) Together for Better Public Services: Partnering with Citizens and Civil Society. Paris: OECD.

Osborne S (2010) Delivering public services: time for a new theory? Public Management Review 12, 1-10.

Osborne S and Brown L (2011) Innovation, public policy and public services delivery in the UK: the word that would be king? Public Administration 89, 1335-1350.

Osborne SP and Strokosch K (2013) It takes two to tango? Understanding the co-production of public services by integrating the services management and public administration perspectives. British Journal of Management 24, S31-S47.

Osborne S, Radnor Z and Strokosch K (2016) Co-production and the co-creation of value in public services: a suitable case for treatment? Public Management Review 18, 639-653.

Ostrom E (1996) Crossing the great divide: coproduction, synergy, and development. World Development 24, $1073-1087$.

Ostrom E (1999) Crossing the great divide: Coproduction, synergy, and development. In McGinnis MD (ed). Readings From the Workshop in Political Theory and Policy Analysis. MI, Ann Arbor: University of Michigan Press.

Pais Y, Polizzi E and Vitale T (2019) Governare l'economia collaborativa per produrre inclusione: attori, strumenti, stili di relazione e problemi di implementazione. In Andreatti A (ed.), Governare Milano nel nuovo millennio. Bologna: Il Mulino, pp. 215-237.

Parks RB, Baker PC, Kiser L, Oakerson R, Ostrom E, Ostrom V, Percy SL, Vandivort MB, Whitaker GP and Wilson R (1981) Consumers as co-producers of public services: some economic and institutional considerations. Policy Studies Journal 9, 1001-1011. 
Pestoff V (2006) Citizens as co-producers of welfare services: preschool services in eight European countries. Public Management Review 8, 503-519.

Pestoff V (2012) Co-production and third sector social services in Europe: some concepts and evidence. Voluntas 23, 1102-1118.

Pestoff V (2014) Collective action and the sustainability of co-production. Public Management Review 16, 383-401.

Polizzi E and Bassoli M (2020) All smoke, no fire? Sharing practices and political investment in two Italian cities. Italian Political Science Review/Rivista Italiana Di Scienza Politica 50, 17-32.

Pollitt C (2016) Managerialism redux? Financial Accountability \& Management 32, 429-447.

Pollitt C and Bouckaert G (2011) Public Management Reform: A Comparative Analysis. New Public Management, Governance, and the Neo-Weberian State. Oxford: Oxford University.

Profeti S and Tarditi V (2019) Le pratiche collaborative per la co-produzione di beni e servizi: quale ruolo per gli Enti locali? Le Istituzioni del Federalismo 4, 861-890.

Rutter J (2016) Innovation in childcare. Nesta. Available at: https://www.nesta.org.uk/report/innovation-in-childcare.

Rutter J and Evans B (2011) Informal Childcare: Choice or Chance. A Literature Review. London: Daycare Trust.

Schon DA (1989) L'intervento pubblico sulle reti sociali informali, in Rivista Trimestrale di Scienza dell'Amministrazione, n.1, pp. 3-47.

Scott W (1987) The adolescence of institutional theory. Administrative Science Quarterly 32, 493-511.

Selzinick P (1957) Leadership in Administration. New York: Harper \& Row.

Sicilia M, Guarini E, Sancino A, Andreani A and Ruffini R (2016) Public services management and co-production in multi-level governance settings. International Review of Administrative Sciences 82, 8-27.

Sicilia M, Sancino A, Nabatchi T and Guarini E (2019) Facilitating co-production in public services: management implications from a systematic literature review. Public Money \& Management 39, 233-240. https://doi.org/10.1080/09540962. 2019.1592904.

Sinclair S, Mazzei M, Baglioni S and Roy MJ (2018) Social innovation, social enterprise, and local public services: undertaking transformation? Social Policy and Administration 52, 1317-1331.

Sørensen E and Torfing J (2011) Enhancing collaborative innovation in the public sector. Administration \& Society 43, 842 868.

Sorrentino M, De Marco M and Rossignoli C (2016) Health care co-production: co-creation of value in flexible boundary spheres. In Borangiu T, Dragoice M and Nóvoa H (eds), Exploring Services Science: 7th International Conference, IESS 2016. Heidelberg Berlin: Springer, pp. 649-659.

Sorrentino M, Guglielmetti C, Gilardi S and Marsilio M (2017). Health care services and the coproduction puzzle: filling in the blanks. Administration \& Society 49, 1424-1449.

Sorrentino M, Sicilia M and Howlett M (2018) Understanding co-production as a new public governance tool. Policy and Society 37, 277-293.

Steen T, Nabatchi T and Brand D (2016) Introduction: special issue on the coproduction of public services. International Review of Administrative Sciences 82, 3-7.

Steinebach Y and Knill C (2017) Social policy in hard times: crisis-coping strategies in Europe from 1976 to 2013. International Journal of Public Administration 40, 1164-1174.

Stinchcombe AL (1968) Social Structure and Organizations. In March JG (ed.), Handbook of Organizations. Chicago: Rand McNally, pp. 142-193.

Torfing J, Andersen LB, Greve C and Klausen KK (2020) Public Governance Paradigms Competing and Co-Existing. Cheltenham: Edward Elgar Publishing.

Vennik FD, van de Bovenkamp HM, Putters K, Grit KJ (2016) Co-production in healthcare: rhetoric and practice. International Review of Administrative Sciences 82, 150-168.

Verschuere B, Brandsen T and Pestoff V (2012) Co-production: the state of the art in research and the future agenda. Voluntas 23, 1083-1101.

Vesan P and Sparano V (2009) Il consolidamento dei partenariati per lo sviluppo locale. Una ricerca sui patti territoriali della provincia di Torino. Rivista italiana di scienza politica/Italian Political Science Review 39, 53-86.

Vitale T (2009) L'impatto istituzionale dell'innovazione sociale. In Vicari Haddock S and Moulaert F (eds), Rigenerare la città. Pratiche di innovazione sociale nelle città europee. Bologna: Il Mulino, pp. 163-198.

Weber M (1968) Economy and Society: An Outline of Interpretative Sociology. New York: Bedminster Press.

Yin RK (1994) Case Study Research: Design and Methods. Thousand Oaks, CA: Sage Publications.

Cite this article: Campomori F, Casula M (2022). Institutionalizing innovation in welfare local services through co-production: toward a Neo-Weberian State? Italian Political Science Review/Rivista Italiana di Scienza Politica 52, 313-327. https:// doi.org/10.1017/ipo.2021.43 